\title{
Quantificar a Probabilidade de Óbitos, uma Pratica Desumana Baseada no Apache II
}

\author{
Silva, Roberto Allan Ribeiro \\ Faculdade Vale do Gorutuba - Favag — robertocxj@yahoo.com.br
}

Introdução: o Brasil conta com 1,3 leitos de Unidade de Terapia Intensiva (UTI) para cada 10.000 habitantes, há um aumento constante na demanda por serviços e sempre haverá uma demanda por serviços maior que a necessidade, sendo que, o aumento da oferta sempre acarreta em aumento da demanda, criando-se assim um sistema de difícil equilíbrio. para contornar tal realidade existe as Centrais de Regulação de Leitos (CRL) que são norteadas pelas diretrizes do Sistema Único de Saúde (SUS), mais em essência são uma forma de racionalizar os recursos disponíveis. um meio de se regular as admissões nesses setores e a partir dos escores do Acute Physiology and Chronic Health Evaluation (APACHE II), um índice prognostico que quantifica a probabilidade de óbito dos pacientes, aqueles com maior chance de morrer são recusado. Objetivos: Analisar os critérios de admissão de pacientes em UTIs de Minas Gerais e demonstrar o quão desumano se mostra esta prática baseada no APACHE II. Métodos: Trata-se de um estudo observacional, prospectivo e quantitativo a ser realizado com pacientes admitidos pela $\mathrm{CRL}$ em UTI-adulto do Norte de Minas. Resultados: Entre os meses de setembro de $2012 \mathrm{e}$ setembro de 2013 foram admitidos 340 pacientes, destes 229 (67\%) vieram do próprio hospital e 111 (33\%) foram admitidos pela central, com uma taxa de óbito de $42 \%$, vale ressaltar que $25 \%$ (37/145) dos óbitos aconteceram com menos de 48 horas de internação. Os diagnósticos primários encontrados foram distribuídos em distúrbios dos sistema neurológico, cardiovascular, respiratório gastrointestinal e metabólicos, pacientes com diagnósticos diferentes dos pré-estabelecidos eram recusados. Todos os pacientes admitidos pela CRL tiveram escore $<28$ pontos, ou seja, não estavam nem muito bem nem muito mal, mas muitos pacientes nem se quer tiveram a chance de entrar na UTI por terem sido considerados críticos de mais e morreram sem assistência devida. Conclusão: como diria Fernando Pessoa, "navegar é preciso; viver não é preciso", nesse sentido o termo "preciso" é apropriado na dimensão de "exatidão", não somente de "necessidade, o poeta sugere que a arte de navegar é uma ciência; já a vida é imprecisa e cercada de incertezas, o que enfatiza a impossibilidade de se quantificar por métodos matemáticos as chances de um paciente ir a óbito. Racionalizar não é a solução, estamos andando na direção errada. Referencias: 1- Associação de Medicina Intensiva Brasileira (AMIB). III Censo Brasileiro de UTIs. 2009. [acesso em 14 jan 2014]. Disponível em: http://www.amib.org.br/CensoAMIB2010.pdf. 2- Dutra, E. C. R, et al. Revista de Administração Hospitalar e Inovação em Saúde (RAHIS ). Experiência de sucesso na implantação de leitos de UT- ad no Norte de Minas Gerais, 2011. 3- CALDEIRA, V. M, et al. Critérios para admissão de pacientes na UTI e Mortalidade. Rev. Assoc Med Bras 2010.

Silva, Roberto Allan Ribeiro. Quantificar a Probabilidade de Óbitos, uma Pratica Desumana Baseada no Apache li. In: Anais do Congresso Internacional de Humanidades \& Humanização em Saúde [= Blucher Medical Proceedings, num.2, vol.1]. São Paulo: Editora Blucher, 2014. ISSN 2357-7282

DOI 10.5151/medpro-cihhs-10701 